\title{
Review
}

\section{Consumer health benefits of habitual consumption of chlorogenic acid-enriched coffee: a large single-arm study}

Kanae Watanabe, Tohru F. Yamaguchi, Tatsuya Kusaura, Hiroshi Hashimoto, Yuichi Iwano, Mitsuhiro Katashima, Yuji Furui

Correspondence to:

Tohru F. Yamaguchi

yamaguchi.tohru@kao.co.jp

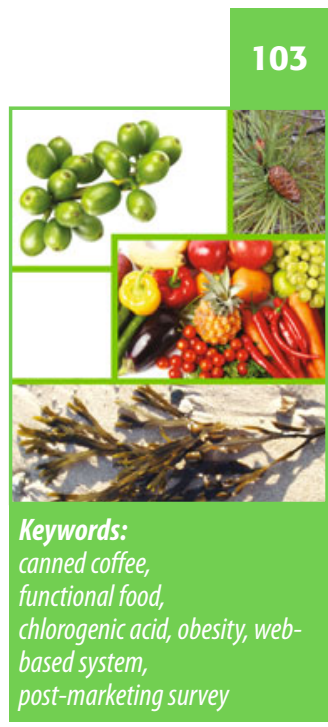

Received: 14 April 2014 / Accepted 11 June 2014

(C) The Author(s) 2014. This article is published with open access at Springerlink.com

\section{Abstract}

Abdominal obesity is considered a fundamental cause of metabolic syndrome. It has been reported that continuous consumption of chlorogenic acid, which is a major component of coffee polyphenols, reduces abdominal fat together with body weight in humans. Chlorogenic acid-enriched ready-todrink coffee has been developed recently. The antiobesity function of chlorogenic acid-enriched coffee has been demonstrated in some clinical trials; however, the efficacy of this coffee in daily life, which is more relevant in terms of consumer health, remains unknown. This paper describes a large single-arm study of the acceptability and effectiveness of chlorogenic acid-enriched coffee in terms of weight loss. Participants received one free

Kanae Watanabe, Yuichi Iwano

Food \& Beverage Business Unit

Kao Corporation

1-14-10 Nihonbashi-Kayabacho, Chuo-ku

Tokyo 103-8210, Japan

Tohru F. Yamaguchi ( $₫)$, Tatsuya Kusaura, Hiroshi Hashimoto, Mitsuhiro Katashima

Health Care Food Research Laboratories

Kao Corporation

2-1-3 Bunka, Sumida-ku

Tokyo 131-8501, Japan

tel +81-3-5630-7475, fax +81-3-5630-7260

yamaguchi.tohru@kao.co.jp carton (30 cans) of chlorogenic acid-enriched coffee and were encouraged to consume one can each day, and record their weight and coffee consumption using a web-based weight-recording system. The chlorogenic acid-enriched coffee showed high consumer acceptability. The mean weight change at Week 12 was $-1.06 \mathrm{~kg}$ (95\% confidence interval: $-0.96,-1.16)$. Weight loss was significantly greater in obese participants compared with those with normal body mass index $\left(<25 \mathrm{~kg} / \mathrm{m}^{2}\right)$ in both men and women. Changes in weight at Week 12 showed a significant dose-response relationship $(p<0.001$, $\mathrm{n}=1659$ ). The habitual consumption of chlorogenic acid-enriched coffee together with the use of a weight-recording system was effective for achieving weight loss in daily life. The popularity of drinking

Yuji Furui

Policy Alternatives Research Institute

The University of Tokyo

7-3-1 Hongo, Bunkyo-ku

Tokyo 113-0033, Japan

Yuji Furui

Healthcare Committee Incorporated

1-28-10 Hongo, Bunkyo-ku

Tokyo 113-0033, Japan 
coffee across all ages suggests a potentially substantial impact from substituting one cup of coffee a day with chlorogenic acid-enriched coffee.

\section{Introduction}

Obesity is a serious health problem worldwide $[1,2]$ and abdominal obesity is considered a fundamental cause of metabolic syndrome [3-6], which leads to insulin resistance and a reduction in insulin secretory function, resulting in the complications of hyperglycaemia, hypertension and hyperlipidaemia. Abdominal obesity [7] is defined as an accumulation of abdominal body fat, which is determined by the balance between energy intake and expenditure [8]. In recent years, many people have struggled to manage this balance because of the increased availability of palatable and hedonic foods, such as high-sugar and/or high-fat foods [9], leading to a potential increase in the need for anti-obesity foods.

The prevalence of obesity is not high in the Japanese population compared with Europe or America [10]. However, a recent meta-analysis suggested that compared with Caucasians, a small decrease in insulin secretory function in East Asians can lead to a large decrease in the threshold level of insulin resistance, above which the onset of type 2 diabetes occurs [11]. East Asians including Japanese tend to be diagnosed with type 2 diabetes without severe obesity. Chlorogenic acid is a major component of coffee polyphenols. Coffee enriched with chlorogenic acid and with reduced hydroxyhydroquinone, an oxidant component, has been studied. It was shown that its metabolites improved vascular endothelial function, and consequently it reduced blood pressure in rodents [12] and in humans [13, 14]. Furthermore, consumption of chlorogenic acid increases fat utilization in rodents $[15,16]$ and in humans [17]. Nagao et al. reported that the continuous consumption of chlorogenic acid-enriched coffee reduced body fat, particularly abdominal fat, together with body weight through increased fat utilization in humans [18].

Chlorogenic acid-enriched ready-to-drink (canned) coffee was developed by Kao Corporation under the brand name Healthya ${ }^{\mathrm{TM}}$. It contains $270 \mathrm{mg}$ chlorogenic acid per can (185 g) with reduced hydroxyhydroquinone. Regular coffee contains approximately 35-175 mg per cup [19]. Canned beverages, including soft drinks such as fruit juice, carbonated beverages, green tea and brewed coffee, are very popular in Japan [20], and can be easily purchased at many types of retailer and vending machines. Canned coffee has the second largest share of the soft drink market in Japan, after carbonated beverages [21]. A canned coffee product with an anti-obesity function is therefore an ideal product to support a population-based public health strategy [22].

The anti-obesity function of chlorogenic acidenriched coffee has been demonstrated in some clinical trials $[17,18]$, therefore it has been approved as a food for specified health use (FOSHU) by the Consumer Affairs Agency, Government of Japan, as a part of product development. However, the efficacy of the coffee in daily life, which is more relevant in terms of consumer health, remains unknown. The purpose of this study was to assess the acceptability and effectiveness of chlorogenic acid-enriched coffee in terms of weight loss in daily life through a large single-arm study.

\section{Materials and methods}

\section{Test beverage}

The test beverage is a canned coffee already on the Japanese retail market (Healthya coffee) which contains $185 \mathrm{~g}$ of brewed coffee without milk and sugar. The coffee is brewed from roasted coffee beans using 2.5 times the volume of roasted coffee beans compared with a conventional brew of coffee, after which the oxidant components, including hydroxyhydroquinone, are removed by filtration. The canned coffee contains approximately $270 \mathrm{mg}$ of chlorogenic acids, including 5-caffeoyl, 3-caffeoyle, 4-caffeoyle, 3-ferulyl, 4-ferulyl and 5-ferulyl quinic acids, and approximately $90 \mathrm{mg}$ of caffeine. The coffee has $9 \mathrm{kcal}$ $(37.7 \mathrm{~kJ})$ of energy composed of $0.5 \mathrm{~g}$ of protein, $0 \mathrm{~g}$ of fat and $1.9 \mathrm{~g}$ of carbohydrate per can. 


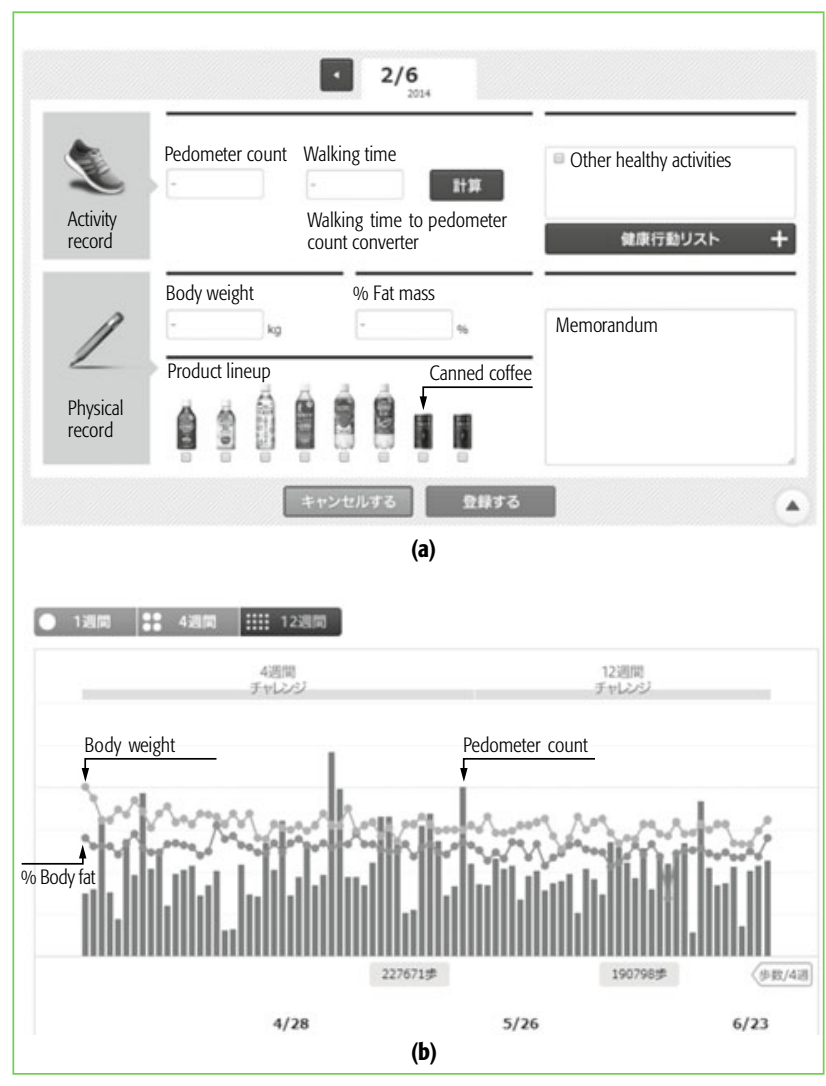

Figure 1 Web-based weight-recording system: (a) web page for data entry; (b) web page for weight monitoring

\section{Study design}

Participants were recruited from the general population, securing a wide variety of Japanese consumers, using several marketing approaches, including poster advertisements in trains, flyers on shop shelves and banner advertising on the product's website. Over 50,000 participants enrolled on the designated website. All participants were provided with one free carton (30 cans) of chlorogenic acid-enriched coffee. Participants were asked to register the day they received the coffee by clicking a button on the web-based weight-recording system provided (Fig. 1). The date of receipt was considered as Day 1 of the 30-day official monitoring period.

Participants were asked to consume the chlorogenic acid-enriched coffee every day for 30 days and to record their weight and coffee consumption using the web-based weight-recording system. The system could record health-related information such as pedometer count, body-fat percentage estimated by bioimpedance measurement, exercise activities and consumption of anti-obesity beverages other than the coffee to maintain their motivation for recording. However, these data were not analysed in the present study. During the 30-day period, participants were sent eight e-mails to remind them to drink the coffee and to record the parameters.

\section{Participants}

Participants were those participants who registered the date of receipt of the coffee. The following participants were excluded from the analysis: participants with particularly low or high weights $(<40$ $\mathrm{kg}$ or $\geq 140 \mathrm{~kg}$ for men, and $<30 \mathrm{~kg}$ or $\geq 130 \mathrm{~kg}$ for women) [23], participants with a percentage weight change $\leq-25 \%$ or $\geq+25 \%$, participants without baseline weight data and participants with no weight data other than baseline weight.

A flow chart of the data-gathering procedure is shown in Fig. 2. All participants agreed to the use of their data for academic studies through a web page on the online system.

\section{Statistical analysis}

The weight-recording system remained accessible after the end of the 30-day monitoring period and the daily records in the system were evaluated for a total of 12 weeks after Day 1 . We defined the period from Day 1 to Day 28 as the 'ad libitum consumption period', and from Day 29 to Day 84 as the 'add-on consumption period'. Baseline weight was defined as the average weight on Days 1-3. The weekly average was defined as the average weight for the subsequent 7-day periods. Where no weight data were available to calculate the weekly average, the data were considered as missing. Statistical analysis was carried out using the data set defined in Fig. 2.

Using all the available data, the probability of Web recording of behaviour $\left(\mathrm{P}_{\mathrm{REC}}\right)$, conditional probabilities of Web recording with coffee consumption 


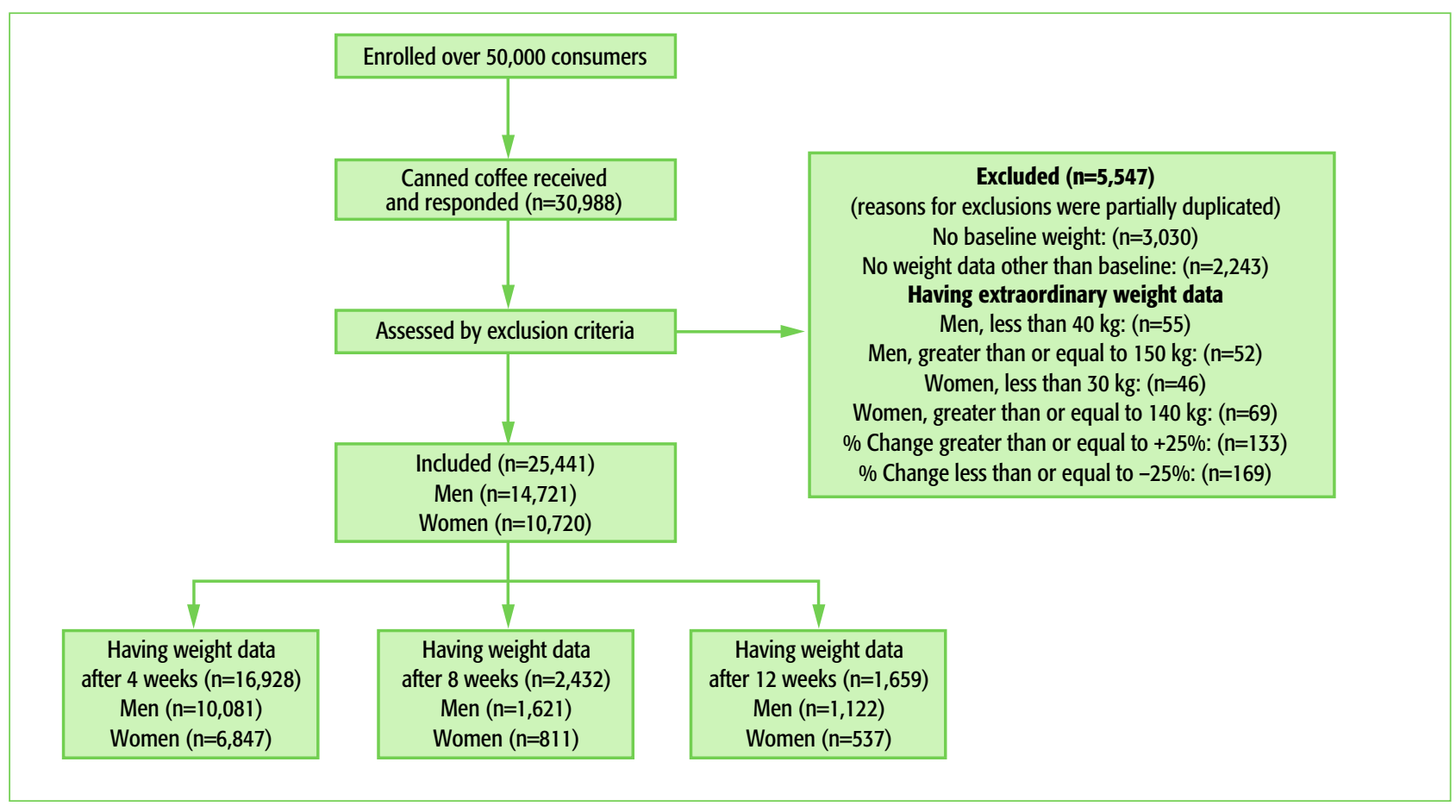

Figure 2 Flow chart showing the data-gathering procedure for statistical analysis

$\left(\mathrm{P}_{\mathrm{REC}} \mathrm{P}_{\mathrm{CONS}}\right)$ and web recording with self-weighing $\left(\mathrm{P}_{\mathrm{REC}} \mid \mathrm{P}_{\text {WEIGH }}\right)$ were estimated individually $(\mathrm{n}=30,988)$ during the 28-day ad libitum consumption period. We analysed how these variables were mutually related using graphical modelling [24].

Statistical analysis was carried out using R statistical analysis software (Version 3.0.2) [25]. $p$ values $<0.05$ were considered as significant in two-tailed statistical tests. Asymptotic confidence intervals (CI) were indicated as error bars.

\section{Results}

\section{Participation}

The number of participants at the beginning of the ad libitum consumption period was 25,441 , which fell to 16,928 by Week 4 , giving a completion rate of $66.5 \%$. Most participants dropped out after Week 4 , because this was the end of the official monitoring period. However, many participants continued to record their coffee consumption and weight and data were available for $2432(9.6 \%)$ participants at Week 8 and 1659 (6.5\%) at Week 12. The sex ratio was $40-42 \%$ women during the ad libitum consumption period and 32-33\% during the add-on consumption period.

\section{Weight loss}

Mean body weight decreased monotonically over the 12-week period (Fig. 3). The mean weight changes were $-0.51 \mathrm{~kg}(95 \% \mathrm{CI}:-0.49,-0.52),-0.84$ $\mathrm{kg}(95 \% \mathrm{CI}:-0.78,-0.91)$ and $-1.06 \mathrm{~kg}(95 \% \mathrm{CI}$ : $-0.96,-1.16)$ at Weeks 4,8 and 12 , respectively (Fig. 3). The sex ratio, age, baseline body weight and baseline body mass index (BMI) also differed significantly between each 4-week period during the 12 weeks (Table 1). The percentage of women decreased at each period, while age, baseline body weight and baseline BMI increased.

Figure 4 shows the mean weight change at Week 12 according to sex and stratified by baseline BMI. Weight loss was significantly greater in obese participants compared with those with normal BMI $(<25)$ in both men and women. A BMI of 25-30 $\mathrm{kg} / \mathrm{m}^{2}$ is considered 'overweight' and a BMI $\geq 30$ 


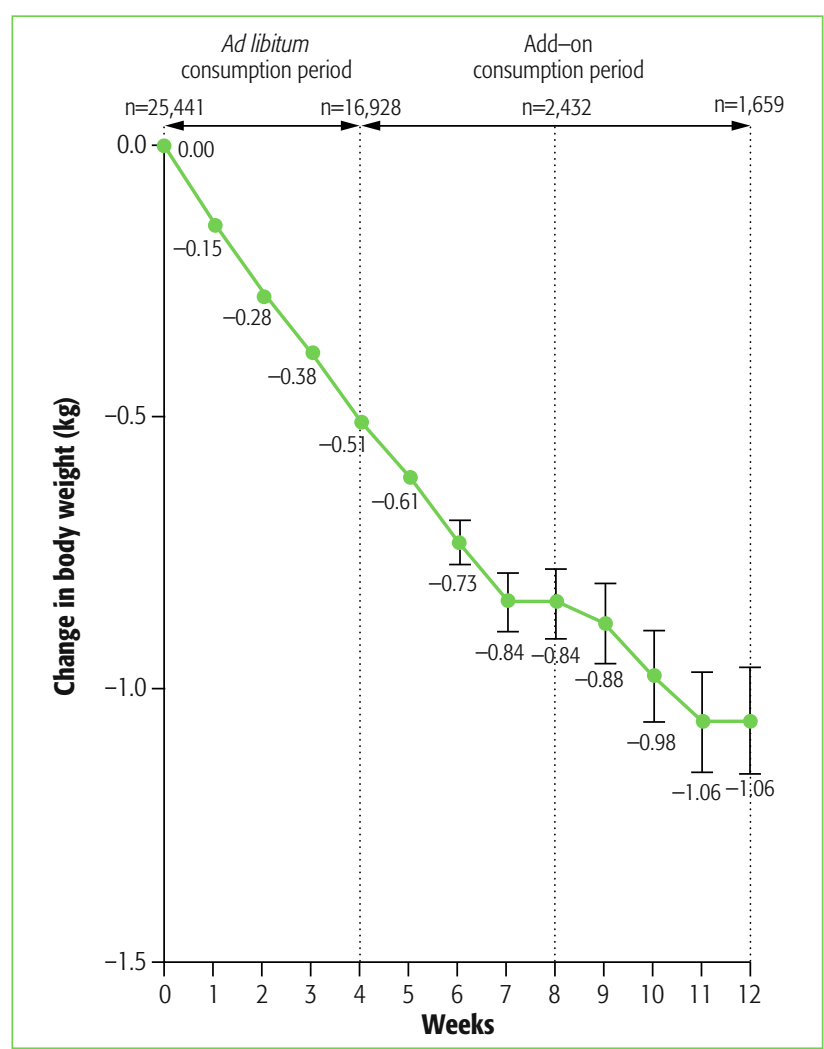

Figure 3 Time course of weight loss. Error bars represent 95\% confidence intervals

$\mathrm{kg} / \mathrm{m}^{2}$ is considered 'obese' according to the World Health Organization (WHO) [26], whereas these

\begin{tabular}{|lccccc}
\hline Time & $\mathbf{n}$ & \% Women & $\begin{array}{c}\text { Age } \\
\text { (years) }\end{array}$ & $\begin{array}{c}\text { Baseline } \\
\text { body weight } \\
\mathbf{( k g )}\end{array}$ & $\begin{array}{c}\text { Baseline } \\
\text { BMI* } \\
\left(\mathbf{k g} / \mathbf{m}^{2}\right)\end{array}$ \\
\hline Baseline & 25,441 & $42 \%$ & $41.4 \pm 9.4$ & $66.4 \pm 13.0$ & $\begin{array}{c}24.0 \pm 3.6 \\
(\mathrm{n}=25,436)\end{array}$ \\
\hline Men & 14,721 & & $42.5 \pm 9.2$ & $73.1 \pm 10.9$ & $24.9 \pm 3.3$ \\
\hline Women & 10,720 & & $39.8 \pm 9.5$ & $57.3 \pm 9.7$ & $22.8 \pm 3.6$ \\
\hline 4 weeks & 16,928 & $40 \%$ & $42.4 \pm 9.3$ & $66.4 \pm 12.8$ & $\begin{array}{c}24.0 \pm 3.5 \\
(n=16,925)\end{array}$ \\
\hline 8 weeks & 2,432 & $33 \%$ & $45.1 \pm 8.8$ & $67.5 \pm 12.5$ & $24.3 \pm 3.4$ \\
\hline 12 weeks & 1,659 & $32 \%$ & $45.3 \pm 8.5$ & $67.6 \pm 12.4$ & $\begin{array}{c}24.3 \pm 3.5 \\
(\mathrm{n}=1,659)\end{array}$ \\
\hline$p$ value & & $<0.001^{\dagger}$ & $<0.001^{\ddagger}$ & $<0.001^{\ddagger}$ & $<0.001 \ddagger$ \\
\hline
\end{tabular}

Mean \pm standard deviation (SD)

*Some BMI values were missing; "differences between time points were analysed statistically; ${ }^{\dagger} \chi^{2}$ test; 'Kruskal-Wallis test

lable 1 Subject demographics

values are defined as 'obese' and 'seriously obese', respectively, by the Japan Society for the Study of Obesity and the Japanese Government [27].

\section{Dose-response relationship with weight loss}

Consumption of more than 30 cans indicated that the participants had purchased more coffee themselves. The relationship between coffee consump- (a)

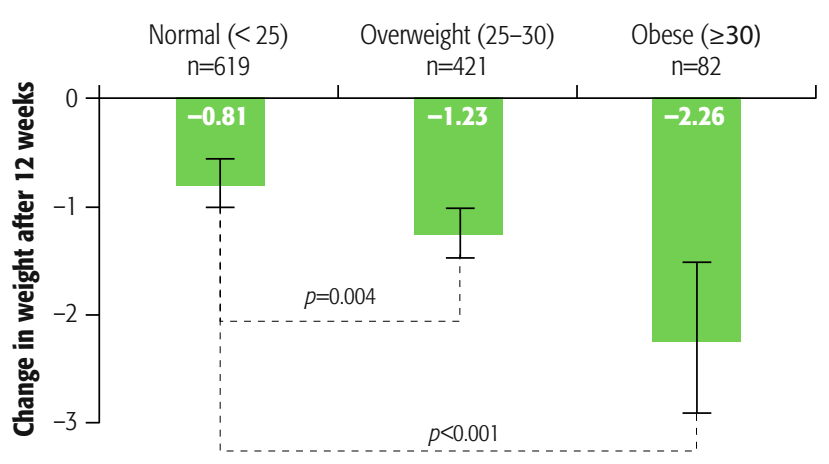

Jonckheere trend test; $p<0.001$ $\mathrm{n}=1,122$ (b)

Body mass index $\left(\mathbf{k g} / \mathbf{m}^{2}\right)$

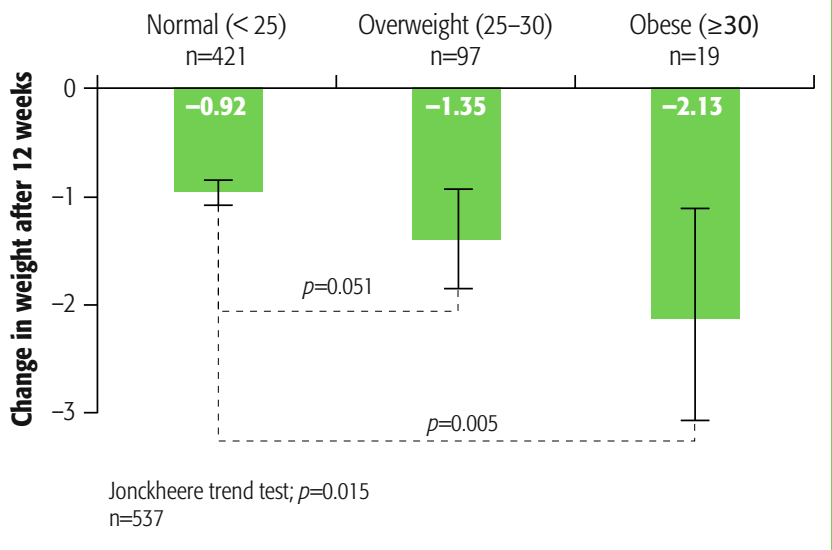

Figure 4 Weight loss stratified by BMI for (a) men and (b) women. The error bars represent $95 \%$ confidence intervals. Comparisons with the normal-BMI groups were made by pooled variance t-tests where $p$ values were adjusted for multiple comparisons by Dunnett's method. A BMI of $25-30 \mathrm{~kg} / \mathrm{m}^{2}$ was considered as 'overweight' and a BMI $\geq 30 \mathrm{~kg} / \mathrm{m}^{2}$ was defined as 'obese' according to the WHO. 
tion and weight change is shown in Fig. 5. There was a significant dose-response relationship according to the Jonckheere trend test $(p<0.001)$. Greater weight loss was observed with increased coffee consumption over 12 weeks. The maximum mean weight change of $-1.62 \mathrm{~kg}$ (95\% CI: $-1.94,-1.30)$ occurred in the highest-dose group (71-84 cans). Subject demographics for each dose group are presented in Fig. 5. There was no significant difference in sex ratio, age or baseline body weight according to the $\chi^{2}$ test and Kruskal-Wallis test.

\section{Relationships between Web recording, coffee consumption and self-weighing}

There was a high correlation between $\mathrm{P}_{\mathrm{REC}} \mid \mathrm{P}_{\text {CONS }}$ and $\mathrm{P}_{\text {REC }} \mid \mathrm{P}_{\text {WEIGH }}(0.829 ; 95 \%$ CI: 0.825, 0.832). Partial correlation coefficients were calculated to exclude the effect of pseudo-correlations. The partial correlation coefficients between $\mathrm{P}_{\mathrm{REC}}$ and $\mathrm{P}_{\mathrm{REC}} \mid \mathrm{P}_{\mathrm{CONS}}$ with $\mathrm{P}_{\mathrm{REC}} \mid \mathrm{P}_{\mathrm{WEIGH}}$ as a covariate, and between $\mathrm{P}_{\mathrm{REC}}$ and $\mathrm{P}_{\text {REC }} \mid \mathrm{P}_{\text {WEIGH }}$ with $\mathrm{P}_{\text {REC }} \mid \mathrm{P}_{\text {CONS }}$ as a covariate were 0.708 (95\% CI: 0.700, 0.716) and 0.605 (95\% CI: $0.596,0.613)$, respectively.

\section{Discussion}

Consumption of chlorogenic acid-enriched coffee was associated with monotonic weight loss during the ad libitum and add-on consumption periods, i.e., $-0.51 \mathrm{~kg}$ at Week $4,-0.84 \mathrm{~kg}$ at Week 8 , and $-1.06 \mathrm{~kg}$ at Week 12. Obese participants lost more weight than normal-weight participants (Fig. 4). These results suggest that habitual consumption of chlorogenic acid-enriched coffee, together with the use of the weight-recording system, supported weight loss during daily life, especially in obese participants.

Out of the total of 25,441 participants, 16,928 (66.5\%) completed the ad libitum consumption period, suggesting good acceptability of the coffee for everyday use, which is an important factor from a public health perspective. Japanese adults drink an average of around 11 cups of coffee a week [28], and substituting one cup of coffee a day with

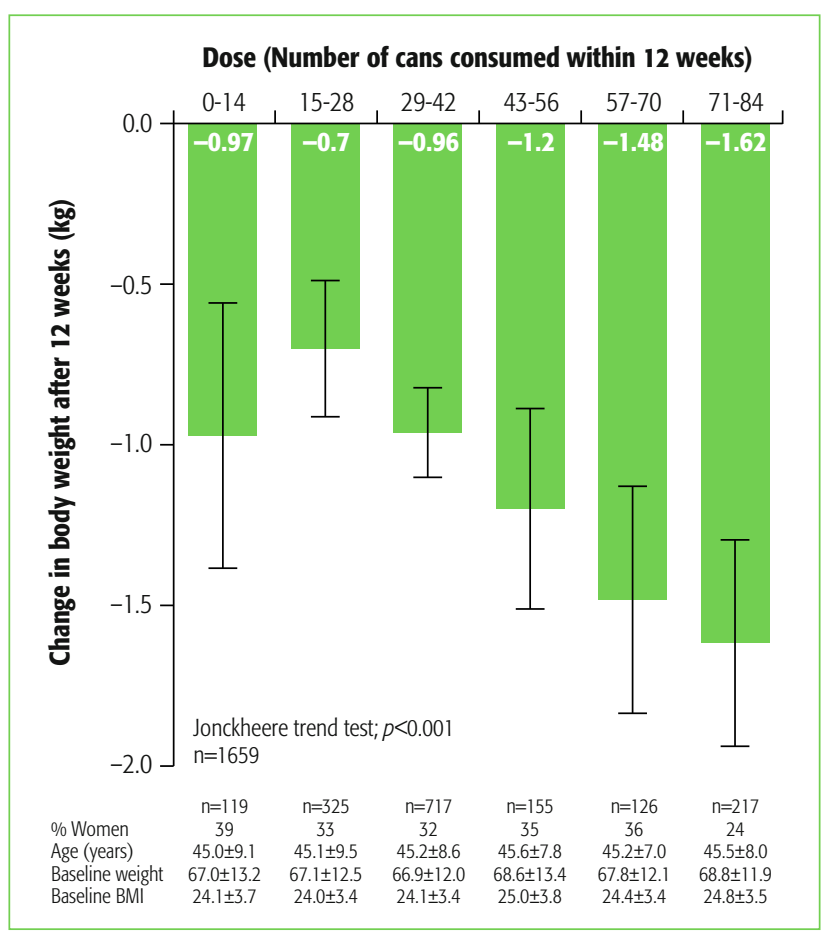

Figure 5 Dose-response relationship for coffee consumption and weight loss after 12 weeks. Error bars represent 95\% confidence intervals. Data are presented as mean $\pm \mathrm{SD}$.

chlorogenic acid-enriched coffee was therefore assumed to be highly acceptable.

There was a significant dose-response relationship between coffee consumption and weight loss over 12 weeks (Fig. 5). The mean weight change at Week 12 was $-1.62 \mathrm{~kg}$ in participants who consumed the coffee every day (71-84 cans in 84 days), which was similar to the weight loss of $-1.5 \mathrm{~kg}$ observed in the earlier 12-week clinical trial [18]. We could not discriminate between the effects of chlorogenic acid and caffeine in terms of weight loss from the results of the present study. However, a placebo beverage used in an earlier study [18] was a caffeinated coffee test beverage, which allows us to infer that the chlorogenic acid was a major contributing factor.

The significantly greater partial correlation coefficient between $\mathrm{P}_{\mathrm{REC}}$ and $\mathrm{P}_{\mathrm{REC}} \mid \mathrm{P}_{\mathrm{CONS}}$ compared with $\mathrm{P}_{\text {REC }}$ and $\mathrm{P}_{\text {REC }} \mid \mathrm{P}_{\text {WEIGH }}$ suggests that Web recording was elicited by coffee consumption, rather than by self-weighing in the ad libitum consumption period. However, coffee consumption and self-weighing 
were highly associated, implying that drinking antiobesity coffee might trigger self-weighing; participants wanted to see the effectiveness of the product, and self-weighing led in turn to Web recording to follow weight reduction progress. This series of behaviours may also help to prevent regaining weight. In addition, the high completion rate of the ad libitum consumption period and the fact that $6.5 \%(n=1659)$ of participants continued voluntary monitoring up to Week 12 suggest that the weight-recording system that allowed participants to visualise their behaviour and progress might help to increase behavioural changes, similar to the so-called monitoring diet [29].

There were some demographic differences between the ad libitum and add-on consumption periods. The percentage of women was smaller during the add-on period, resulting in a higher baseline weight and BMI. This suggests that the motivation for and dedication to weight loss might differ between men and women, possibly associated with the fact that men have a higher prevalence of metabolic syndrome [30].

One of the limitations of the present study was compliance monitoring, owing to the difficulty of confirming data for such a large number of participants. However, imprecision in measurement of weight is not likely to be a serious issue [31] compared with most biochemical or physiological measurements. Furthermore, digital bathroom-type scales are commonly used at home in Japan, thus the precision is much higher than with the use of spring-type scales, which were popular before 2000. A further limitation was the lack of a control group. However, adopting the single-arm study design approach enabled us to enroll a large number of participants from a wide population, because it was much easier to obtain their informed consent compared with a randomised controlled trial design approach.

The observed weight loss within 12 weeks could be considered to be relatively small $(-1.06 \mathrm{~kg})$. However, a meta-analysis of 25 randomised control trials has estimated that a decrease of $1 \mathrm{~kg}$ in body weight corresponded to decreases of 1.05 and 0.92 $\mathrm{mmHg}$ in systolic and diastolic blood pressures, respectively [32]. Moreover, Japanese people tend to be diagnosed with type 2 diabetes without associated severe obesity [11]. These facts suggest that a small change in body weight in the general population could have a significant impact on public health. In addition, the wide acceptability of the chlorogenic acid-enriched coffee makes this a good option for those that are unaware of the risk of diabetes and showing no typical signs of obesity.

Although there was no significant difference in demographics between dose groups at Week 12, the habitual consumption of chlorogenic acid-enriched coffee might not be the only cause of the weight loss. It is possible that behavioural changes, such as exercise habits, food selection and eating habits, might also be related. Further studies are needed to investigate how lifestyle behaviour may change in relation to the habitual consumption of chlorogenic acid-enriched coffee.

\section{Conclusions}

The habitual consumption of chlorogenic acid-enriched coffee together with the use of a weightrecording system was effective for achieving weight loss in daily life. Weight loss increased with increasing coffee consumption over 12 weeks. Furthermore, the habitual consumption of chlorogenic acid-enriched coffee triggered self-weighing, which led to participants Web recording their daily behaviour. Importantly, this chlorogenic acid-enriched coffee showed good consumer acceptability. The popularity of drinking coffee across all ages suggests a potentially substantial impact of substituting one cup of coffee a day with chlorogenic acid-enriched coffee.

\section{Conflict of interest}

This study was supported by Kao Corporation, the manufacturers of Healthya canned coffee. Kanae Watanabe, Tohru F. Yamaguchi, Tatsuya Kusaura, Hiroshi Hashimoto, Yuichi Iwano and Mitsuhiro Katashima are employees of Kao Corporation. Yuji 
Furui is also president of Healthcare Committee Inc., which is partially funded by Kao Corporation.

\section{Human and Animal Rights}

All procedures followed were in accordance with the Helsinki Declaration of 1975, as revised in 2005.

\section{Informed consent}

Informed consent was obtained from all participants for inclusion in the study.

\section{References}

1. Blundell JE, Hebebrand J, Oppert J-M (2010) What is the value of obesity research? Obes Facts 3:279-282

2. Berrington de Gonzalez A, Hartge P, Cerhan JR, et al (2010) Body-mass index and mortality among 1.46 million white adults. N Engl J Med 363:2211-2219

3. Cornier M-A, Dabelea D, Hernandez TL, Lindstrom RC, Steig AJ, Stob NR, Van Pelt RE, Wang H, Eckel RH (2008) The metabolic syndrome. Endocr Rev 29:777-822

4. Kohro T, Furui Y, Mitsutake N, Fujii R, Morita H, Oku S, Ohe K, Nagai R (2008) The Japanese national health screening and intervention program aimed at preventing worsening of the metabolic syndrome. Int Heart J 49:193-203

5. Ford ES, Giles WH, Dietz WH (2002) Prevalence of the metabolic syndrome among US adults: findings from the third National Health and Nutrition Examination Survey. JAMA 287:356-359

6. Matsuzawa Y, Funahashi T, Nakamura T (2011) The concept of metabolic syndrome: contribution of visceral fat accumulation and its molecular mechanism. J Atheroscler Thromb 18:629-639

7. Després J-P, Lemieux I (2006) Abdominal obesity and metabolic syndrome. Nature 444:881-887

8. Hall KD, Heymsfield SB, Kemnitz JW, Klein S, Schoeller DA, Speakman JR (2012) Energy balance and its components: implications for body weight regulation. Am J Clin Nutr 95:989-994

9. Zheng H, Lenard NR, Shin AC, Berthoud HR (2009) Appetite control and energy balance regulation in the modern world: reward-driven brain overrides repletion signals. Int J Obes 33[Suppl 2]:8-13

10. Kelly T, Yang W, Chen C-S, Reynolds K, He J (2008) Global burden of obesity in 2005 and projections to 2030. Int J Obes (Lond) 32:1431-1437

11. Kodama K, Tojjar D, Yamada S, Toda K, Patel CJ, Butte AJ (2013) Ethnic differences in the relationship between insulin sensitivity and insulin response: a systematic review and meta-analysis. Diabetes Care 36:1789-1796

12. Suzuki A, Fujii A, Yamamoto M, Ohminami H, Kameyama A, Shibuya Y, Nishizawa Y, Tokimitsu I, Saito I, Yamamoto
N (2006) Improvement of hypertension and vascular dysfunction by hydroxyhydroquinone-free coffee in a genetic model of hypertension. FEBS Lett 580:2317-2322

13. Yamaguchi T, Chikama A, Mori K, Watanabe T, Shioya Y, Katsuragi Y, Tokimitsu I (2008) Hydroxyhydroquinone-free coffee: a double-blind, randomized controlled dose-response study of blood pressure. Nutr Metab Cardiovasc Dis 18:408-414

14. Chikama A, Yamaguchi T, Ochiai R, Kataoka K, Tokimitsu I (2008) Effects of hydroxyhydroquinone-reduced coffee on blood pressure in high-normotensives and mild hypertensives. J Health Sci 54:162-173

15. Murase T, Misawa K, Minegishi Y, Aoki M, Ominami H, Suzuki Y, Shibuya Y, Hase T (2011) Coffee polyphenols suppress diet-induced body fat accumulation by downregulating SREBP-1c and related molecules in C57BL/6J mice. Am J Physiol Endocrinol Metab 300:E233-E133

16. Murase T, Yokoi Y, Misawa K, Ominami H, Suzuki Y, Shibuya Y, Hase T (2012) Coffee polyphenols modulate whole-body substrate oxidation and suppress postprandial hyperglycaemia, hyperinsulinaemia and hyperlipidaemia. Br J Nutr 107:1757-1765

17. Ota N, Soga S, Murase T, Shimotoyodome A, Hase T (2010) Consumption of coffee polyphenols increases fat utilization in humans. J Health Sci 56:745-751

18. Nagao T, Ochiai R, Watanabe T, Kataoka K, Komikado M, Tokimitsu I, Tsuchida T (2009) Visceral fat-reducing effect of continuous coffee beverage consumption in obese subjects. Jpn Pharmacol Ther 37:333-344

19. Chu Y-F (2012) Coffee: emerging health effects and disease prevention. Wiley-Blackwell/IFT Press, Ames, IA

20. Grinshpun H (2013) Deconstructing a global commodity: coffee, culture, and consumption in Japan. J Consum Cult. doi: $10.1177 / 1469540513488405$

21. Japan Soft Drink Association (2013) Changes in output of soft drinks by item. http://j-sda.or.jp/about-jsda/english/sdstatistics/sd-statistics03.php. Accessed 3 Jun 2014

22. Rose G (1985) Sick individuals and sick populations. Int J Epidemiol 14:32-38

23. Health and Nutrition Information Study Group, Ministry of Health Labour and Welfare (2013) The national nutrition survey in Japan. Dai-ichi Shuppan Publishing, Tokyo

24. Højsgaard S, Edwards D, Lauritzen SL (2012) Graphical models with R. Springer, New York

25. Ihaka R, Gentleman R (1996) R: a language for data analysis and graphics. J Comput Graph Stat 5:299-314

26. Lorenzo C, Williams K, Hunt KJ, Haffner SM (2007) The National Cholesterol Education Program: Adult Treatment Panel III, International Diabetes Federation, and World Health Organization definitions of the metabolic syndrome as predictors of incident cardiovascular disease and diabetes. Diabetes Care 30:8-13

27. Matsuzawa Y (2005) Metabolic syndrome: definition and diagnostic criteria in Japan. J Atheroscler Thromb 12:301 
28. All Japan Coffee Association (2012) Coffee market in Japan. http://coffee.ajca.or.jp/wp-content/uploads/2012/07/coffee_market_in_japan.pdf. Accessed 3 Jun 2014

29. Vanwormer JJ, French SA, Pereira MA, Welsh EM (2008) The impact of regular self-weighing on weight management: a systematic literature review. Int J Behav Nutr Phys Act 5:54

30. Ryo M, Nakamura T, Funahashi T, et al (2011) Health education "Hokenshido" program reduced metabolic syndrome in the Amagasaki visceral fat study. Three-year follow-up study of 3,174 Japanese employees. Intern Med 50:1643-1648

31. Willett W (1998) Anthropometric measures and body composition. In: Willett W (ed) Nutritional epidemiology, 2nd edn. Oxford University Press, New York, pp 244-272

32. Neter JE, Stam BE, Kok FJ, Grobbee DE, Geleijnse JM (2003) Influence of weight reduction on blood pressure: a metaanalysis of randomized controlled trials. Hypertension 42:878-884 